\title{
ATENÇÃO FARMACÊUTICA: NEM SÓ DE MEDICAMENTO VIVE UMA FARMÁCIA
}

\author{
PHARMACEUTICAL CARE: PHARMACIES CANNOT LIVE ON MEDICATION
}

ALONE

Recebido em: 14/03/2018 • Aprovado em: 18/06/2018

Avaliado pelo sistema double blind review Editor Científico: Edson Sadao Iizuka DOI 10.13058/raep.2018.v19n3.1043

\section{STELA CRISTINA HOTT CORRÊA stelachc@gmail.com ALCIELIS DE PAULA NETO}

UniversidAde Federal de JUIZ dE Fora

\section{MARLUSA GOSLING}

Universidade Federal de Minas Gerais

\section{RESUMO}

Este caso descreve a trajetória percorrida por uma equipe de professores para implantar uma farmácia universitária. Muitos desafios foram superados nessa empreitada até que, para avançar na abertura do serviço, a equipe teve de conhecer as atitudes, motivações e expectativas de seu público-alvo. Neste sentido, foram organizados cinco grupos focais. Diante dos resultados da pesquisa, o discente é convidado a tomar o lugar da principal tomadora de decisão para estabelecer o posicionamento da oferta da farmácia e as ações de marketing de serviço necessárias ao seu lançamento. Desse ponto de vista, o caso propõe uma tomada de decisão explícita. No entanto, oferece oportunidade do discente analisar as condições de uso dos grupos focais, sugerindo soluções alternativas para os seus pontos passíveis de crítica, e interpretar o empreendimento de acordo com a lógica serviço-dominante. Este é um caso real e seu debate objetiva aproximar o aluno das reflexões práticas acerca de posicionamento, marketing de serviço, grupos focais e lógica serviço-dominante. Palavras-chave: Grupos focais, Marketing de serviço, Lógica serviço-dominante, Posicionamento, Atenção farmacêutica.

\begin{abstract}
This case describes the journey taken by a team of teachers to establish a university pharmacy. In order to advance to the opening of the service, the team had to know the attitudes, motivations and expectations of its target audience. Thus, five focus groups were organized. Given the results of the research, students are invited to take the place of the main decision-maker and establish the positioning of the pharmacy's offerings and the service marketing actions required to launch it. From this point of view, the case proposes an explicit taking of decisions; however, it also allows students to analyze the focus groups' conditions of use by proposing alternative solutions to their critical issues and interpret the undertaking according to Servicedominant Logic. This is a real case and its discussion aims to bring students closer to practical thinking about Positioning, Service Marketing, Focus Groups and Service-dominant Logic.

Keywords: focus groups, service marketing, service-dominant logic, positioning pharmaceutical care
\end{abstract}




\section{INTRODUÇÃO}

“- Minha mãe usava o chá de boldo para dor de barriga e eu uso também!" Patrícia Moraes abriu um sorriso diante do comentário da senhora Z. Eram 18 horas e ela revia alguns vídeos deixados pelo professor Álvaro Dias, depois da reunião realizada naquela tarde com a Comissão para planejamento da abertura da farmácia universitária da Universidade Federal do Vale do Suaçuí (UFVS). Os vídeos registravam os grupos focais realizados com os moradores do bairro Santa Isabel. Patrícia era coordenadora do curso de Farmácia e assistia agora com cuidado aos comentários dos entrevistados sobre a atenção farmacêutica para entender o seu comportamento. Afinal, a primeira turma do curso de Farmácia já estava indo para o sexto período e a farmácia-escola contribuiria com a sua formação, além de estar no projeto pedagógico do curso. Para implantá-la, muitas decisões precisavam ser tomadas. Como atrair o público? Como divulgar a farmácia? Quanto cobrar pelos serviços?

\section{A FARMÁCIA UNIVERSITÁRIA EM RETROSPECTIVA}

A Universidade Federal do Vale do Suaçuí foi inaugurada em 2013, na cidade de Suaçuí, no norte mineiro. Em 2016 sua população era de aproximadamente 270 mil habitantes, que trabalhavam, majoritariamente, no comércio e na prestação de serviços. A renda média per capita da população girava em torno de dois salários mínimos. Quando a UFVS foi inaugurada, ela era a única instituição de ensino superior gratuita da cidade, já que contava com mais três instituições privadas. No entanto, a universidade se destacou entre as demais, tornando-se um polo de atração para jovens do centro norte do estado, que antes tinham de se deslocar para outras cidades ou até para outros estados para estudarem numa universidade pública.

Nesse contexto, foram abertos dez cursos, dentre os quais, Farmácia, cuja grade curricular privilegiava diversas áreas das ciências farmacêuticas, com ênfase para medicamentos, análises clínicas e alimentos. Depois de três anos criado, o curso estava na iminência da concretização da sua farmácia universitária. Patrícia Moraes, aos 32 anos, assumiu a coordenação 
do curso com determinação e trazia em seu currículo um pós-doutorado, sendo uma referência em química orgânica. Apesar de sua inexperiência em gestão, tinha vencido os inúmeros obstáculos para a consolidação do curso e o seu mais novo desafio residia na abertura da farmácia universitária. O projeto pedagógico previa a sua abertura para que o aluno pudesse integrar a teoria com a prática profissional. Além disso, era uma grande oportunidade para a oferta de serviços e produtos para os pacientes, as famílias e a comunidade da região.

Em abril de 2014, Patrícia começou essa articulação. Durante uma reunião para debater os projetos de extensão da universidade, travou conheciemnto com o professor Álvaro Dias do curso de Administração que, aos 38 anos, tinha rica experiência acadêmica e prática como consultor de empresas. Recentemente empossado na universidade, estava disposto a contribuir com seu crescimento. Sendo um entusiasta do planejamento estratégico, defendia que muitas práticas administrativas utilizadas na iniciativa privada poderiam ser plenamente incorporadas ao serviço público para agregar valor aos seus usuários.

Após longa conversa, Patrícia conclui ser inviável a abertura de uma farmácia universitária sem um planejamento que contemplasse a análise do setor e do público-alvo. Por isso, iniciaram um projeto interdisciplinar para o seu planejamento que tratou desde a análise do macro e microambiente, a realização das pesquisas de marketing, até a confecção de um plano de negócios norteador da implantação da farmácia que resultaria num trabalho de fôlego. O professor Álvaro convidou a professora Selena Coimbra para auxiliar nas pesquisas, pois esta trabalhava havia muitos anos com pesquisa de marketing e comportamento do consumidor, tendo orientado muitos alunos na abertura de negócios. Além disso, do Departamento de Farmácia, participaram os técnicos administrativos Clara Antunes e Orlando Azevedo e foram integrados ao grupo quatro alunos bolsistas do projeto.

De partida, Álvaro e Patrícia realizaram uma pesquisa exploratória para conhecer melhor o negócio, visitaram farmácias universitárias de referência no país e trocaram experiências com os profissionais participantes do Encontro Nacional de Farmácias Universitárias, promovido em Goiâ- 
nia, em 2014. Todas as iniciativas sondadas incorporavam particularidades específicas de seu público e suas cidades. Assim, desde cedo, os professores notaram a importância de trabalharem com inovação e criatividade para se criar um modelo de farmácia universitária em consonância com as características legais, culturais e políticas de Suaçuí.

O primeiro desafio referia-se à restrição orçamentária, em face disso, a farmácia não seria uma farmácia magistral visto que isso exigiria um investimento do qual a universidade não dispunha. Uma saída seria oferecer serviços farmacêuticos e revender medicamentos comprados de outros laboratórios, ou até mesmo de outras farmácias magistrais. Uma das farmácias visitadas funcionava dessa forma, e esta poderia ser um benchmark. Álvaro observou também o modelo de negócio das farmácias e drogarias privadas, principalmente as grandes redes, e notou que eram verdadeiras lojas de conveniência e minimercados. Além disso, vinham agregando a atenção farmacêutica no seu leque de ofertas de serviços. Nesse mercado, as pequenas farmácias sobreviviam, mas enfrentavam dificuldades diante da competição.

Outro desafio consistia na localização da farmácia, pois, inicialmente se pensou em montá-la fora do campus. Para descobrir um ponto, os próprios pesquisadores fizeram uma visita in loco nas instalações selecionadas e, por isso, foram aplicadas técnicas de observação e entrevistas informais com o intuito de avaliar as condições das instalações e, sobretudo, sondar a vizinhança a respeito dos fatores favoráveis e desfavoráveis em relação aos respectivos imóveis. Uma vez efetuado um levantamento preleminar de alguns imóveis de interesse para a locação, os professores definiram critérios preliminares para a sua seleção, baseados nos seguintes pontos: a) o imóvel deveria ser localizado no centro da cidade; b) o imóvel deveria estar desocupado e disponível para locação imediata; c) a documentação do imóvel deveria estar plenamente viável (certificados de débitos em dia etc.); d) o imóvel deveria ter disponibilidade para adequações e reformas por parte do proprietário para os atendimentos das exigências técnicas e jurídicas legais; e) o imóvel deveria ter área superior ou igual a $220 \mathrm{~m}^{2}$; f) o valor do aluguel deveria ter um teto no máximo de cinco mil reais. 
A partir desse levantamento, Álvaro recrutou, voluntariamente, especialistas ou determinadas personalidades que tivessem um grau considerável de experiência acerca dos mercados imobiliário, farmacêutico e comercial de Suaçuí. Esses voluntários foram estimulados a visitarem e apreciarem pessoalmente os imóveis selecionados e a opinarem sobre as possibilidades desses para a finalidade almejada. Inclusive um dos especialistas foi considerado uma pessoa estratégica para a decisão acerca do projeto, haja vista suas credenciais: técnico em farmácia, dono de uma rede de farmácias na cidade e secretário da fazenda em atividade da prefeitura local. Esses especialistas se transformariam nos consultores do projeto.

De quatro imóveis analisados, Álvaro indicou dois para que Patrícia e o departamento decidissem sobre a locação, visto que, comercialmente, representavam os melhores pontos. No entanto, o ano de 2015 iniciava repleto de crise econômica e a Sub-Reitora de Planejamento, Orçamento e Finanças, Carla Helena, descartou as escolhas, embora comercialmente excelentes. Esta considerou aproveitar uma construção federal no bairro Santa Isabel, localizado distante do centro, para construir a farmácia, apesar de não ser a melhor opção. A construção apresentava diversos problemas de infraestrutura, era afastada do centro comercial e ficava num bairro relativamente populoso, mas de difícil acesso para o restante da população. Diante disso, Patrícia e Álvaro remodelaram os planos que, já em andamento, deveriam se deter nas peculiaridades do bairro Santa Isabel para instalar a farmácia universitária.

\section{ATENÇÃO FARMACÊUTICA}

A partir da localização imposta pela Sub-Reitoria, Álvaro e Patrícia começaram a planejar a reforma das novas instalações da farmácia universitária no bairro Santa Isabel. O planejamento ia adiantado, quando em julho de 2015, Patrícia ligou para Álvaro com uma notícia bombástica: “- Inicialmente, não poderemos contar com a venda de medicamentos. A Sub-Reitoria de Planejamento, Orçamento e Finanças não poderá subsidiar as compras iniciais de medicamento para a revenda". Como abrir uma farmácia universitária sem medicamentos? Mais um desafio à frente. Um detalhe chama 
a atenção no caso: os fatores que conspiram contra a iniciativa, por mais paradoxal que possa parecer, são os fatores que fazem o projeto acontecer. Os proponentes do projeto não se arrefecem diante de tantas dificuldades e sempre procuram soluções alternativas para o seu êxito. Álvaro incentiva a Comissão com noções de empreendedorismo e o grupo absorve não somente os conceitos de planejamento, organização, direção e controle, bem como a noção de eficiência, eficácia e efetividade. A todo instante, o grupo superava barreiras, aprendia com os erros e caminhava para adiante.

Isso ocorreu mais uma vez. Clara Antunes, a futura técnica administrativa da farmácia, teve a ideia de conversar com o Secretário de Saúde do município para tentar ajustar uma parceria em que a farmácia se converteria em um ponto de distribuição de medicamentos complementares aos postos de saúde. Por sua vez, Patrícia lembrou que, na fase inicial do planejamento, durante as conversas com os consultores, havia sido identificado que os pacientes da região tinham muitos problemas relacionados à adesão ao tratamento. Esses problemas incluíam situações até curiosas: pacientes que não usavam os medicamentos prescritos, pacientes que usavam medicamentos que não foram prescritos, pacientes que usavam uma dose inferior à indicada pelo médico, pacientes que paravam de tomar o medicamento sem completar o período necessário ao tratamento, e situações de reações adversas.

Diante do exposto, Patrícia sugeriu que a farmácia universitária deveria ofertar também um serviço de atenção farmacêutica, isto seria um diferencial gerador de valor para o paciente e os familiares. Por intermédio da atenção farmacêutica, o farmacêutico poderia estender suas ações para a atenção primária da saúde, tendo o medicamento como insumo e o paciente como objetivo, uma vez que a atenção farmacêutica consiste na provisão responsável da farmacoterapia, com o propósito de alcançar resultados concretos em resposta à terapêutica prescrita, melhorando a qualidade de vida do paciente.

Em uma das reuniões do grupo, Selena salientou que, com o serviço de atenção farmacêutica, a farmácia teria como formar um caixa inicial que funcionaria como capital de giro, viabilizando a compra futura de medicamentos e insumos. Portanto, poderia se obter a autossustentabilidade, pois 
a dependência crônica do aporte de recursos públicos para a manutenção da farmácia seria muito instável. Qualquer mudança de reitoria, chefia departamental ou crise econômica poderia inviabilizar o projeto. Além disso, parcerias com o setor público, por exemplo, com prefeituras municipais são sempre muito frágeis e sujeitas à ingerência. O ideal era que a farmácia tivesse condições de faturar o suficiente para cobrir os seus custos e ainda promover investimentos de melhoria contínua e sofisticação. Para tanto, seria necessário um superávit nas receitas em detrimento das despesas.

A farmácia operaria independentemente das dotações orçamentárias do departamento e ficaria imune às variações políticas da universidade. Portanto, o núcleo de ação deveria ser a atenção ao paciente, tornando-o engajado e multiplicador de outros pacientes por meio do marketing de relacionamento e da comunicação boca a boca. Desse modo, definiu-se que a farmácia universitária da UFVS teria um propósito didático-pedagógico de ensino e aprendizagem na ciência farmacêutica e de atendimento social relevante à comunidade de Suaçuí por meio da dispensação de medicamentos e da atenção farmacêutica aos pacientes.

\section{OS GRUPOS FOCAIS}

Para o estabelecimento da atenção farmacêutica, deveria se decidir sobre o seu posicionamento, além de outras questões operacionais como o horário de atendimento, perfil do profissional prestador do serviço, precificação, ambiência física do espaço do serviço, comunicação de marketing, dentre outros. Deduziu-se que sem uma pesquisa de marketing ficaria dificil tomar essas decisões, pois seria necessário conhecer as expectativas e a atitude do público-alvo em relação ao conceito de "atenção farmacêutica".

A professora Selena sugeriu que fossem realizados grupos focais com o público-alvo potencial para buscar respostas para essas questões. A entrevista focada em grupo é um tipo de entrevista em que a integração espontânea dos participantes propicia riqueza de opiniões e experiências, ajudando o pesquisador a refinar conceitos referentes ao assunto. Estas são particularmente empregadas em serviços quando se deseja conhecer as características e dimensões de qualidade, as preferências, os hábitos, as percepções e as atitudes dos consumidores. 
Selena planejou os roteiros de entrevistas de acordo com o público a ser entrevistado. Os consultores já haviam indicado que a compra de medicamentos na família é realizada predominantemente por mulheres. Portanto, a professora pretendia organizar grupos com mulheres da terceira idade e mulheres jovens adultas. No entanto, o professor Álvaro tinha a intenção de entrevistar também o público mais jovem, entre quinze e vinte e dois anos, para investigar se esse público formava um nicho de mercado, com necessidades específicas deles.

Álvaro fez contato com padre Daniel, da igreja principal do bairro, que lhe franqueou o acesso a Dimas, professor de educação física para mulheres da terceira idade na própria paróquia, e à Marlene, profissional de psicologia que mantinha um grupo de debate sobre saúde e vícios com jovens mulheres adultas. Dimas e Marlene revelaram-se essenciais no recrutamento de participantes mulheres e de adolescentes do ensino médio da rede de ensino particular. Outro contato relevante foi a diretora da escola estadual de ensino médio, por intermédio da qual, tornou-se possível montar um grupo focal com alunos do ensino médio da rede pública.

Durante o recrutamento de participantes, padre Daniel e Álvaro resolveram obter informações dos profissionais do posto de saúde do bairro que serviria para acrescentar mais informações sobre o comportamento do público. Desta feita, padre Daniel entregou a Álvaro o contato do Dr. Francisco, médico diretor do posto de saúde, que facilitou a organização de um grupo focal com os profissionais do posto.

Assim, os moradores e frequentadores do bairro onde seria instalada a farmácia formaram o público-alvo das entrevistas. Foram realizados seis grupos focais com estes e cada grupo tinha cerca de dez a treze participantes, os quais embora apresentassem características semelhantes, não necessariamente atitudes. Eram compostos de mulheres da terceira idade, profissionais de saúde do posto de saúde do bairro Santa Isabel, mulheres jovens adultas e estudantes do ensino médio, com dois grupos formados por alunos de um curso noturno (escola pública) e de um curso matutino de escolas particulares. 


\section{OBJETIVOS DOS GRUPOS FOCAIS}

O objetivo dos grupos focais ficou assim estabelecido: identificar quais eram as expectativas e atitude do público do bairro Santa Isabel em relação ao serviço de atenção farmacêutica a ser oferecido pela farmácia universitária da UFVS. Esse objetivo se desdobrou nos seguintes objetivos secundários: apontar as motivações que levavam o público a buscar a assistência de um serviço de saúde; detectar os tipos de assistência à saúde mais solicitados; conhecer quais eram os grupos de referência do público-alvo; avaliar o nível de conscientização e conhecimento do público em relação ao conceito de atenção farmacêutica; observar as situações que levavam à necessidade de utilização de uma sala reservada para a atenção farmacêutica; identificar os sentimentos do público em relação ao conceito do serviço de atenção farmacêutica; determinar as expectativas do público em relação ao serviço de atenção farmacêutica da farmácia universitária da UFVS quanto ao atendimento pessoal, horários de atendimento, aparência da sala, preço, público-alvo; identificar os sentimentos em relação a um serviço de atenção farmacêutica a ser oferecido pela farmácia universitária da UFVS; e, finalmente, identificar os meios de comunicação mais adequados para a divulgação do serviço de atenção farmacêutica da UFVS.

Todas as entrevistas foram mediadas pelo mesmo moderador e dirigidas por roteiros especificamente elaborados para cada grupo, de acordo com a sua especificidade e os propósitos da pesquisa. Com autorização dos entrevistados, as entrevistas foram gravadas e/ou filmadas, o que possibilitou uma melhor análise dos dados. Os problemas direcionadores dos grupos focais foram: Quais seriam as expectativas do público para o serviço de atenção farmacêutica? E qual seria a atitude do público em relação à atenção farmacêutica, ou seja, quais seriam suas percepções cognitivas, afetivas e comportamentais em relação à atenção farmacêutica?

$\mathrm{Na}$ condução das entrevistas Selena inquiriu sobre as diferenças nas perspectivas, comparando-as e contextualizando-as. Sempre que necessário, os entrevistados foram solicitados a teorizar, ou seja, explicar o porquê de terem essas visões diferentes e fornecerem significados ou definições aos 
conceitos emitidos. Os pesquisadores ficaram atentos para todas as respostas, divergentes ou similares, independentes de sua frequência, pois alargariam o entendimento sobre o tema.

Como material de estímulo para os participantes, Selena selecionou fotos de farmácias universitárias e pessoas doentes. Inicialmente as discussões eram direcionadas para o conceito de farmácia universitária, em seguida, as questões se dirigiam para o conceito e expectativas em relação à atenção farmacêutica, e por fim, sugestões acerca do serviço eram ouvidas. Um vídeo em que atores encenavam um atendimento típico do serviço de atenção farmacêutica foi utilizado para ilustrar esse serviço.

Posteriormente, os dados foram transcritos em tabelas previamente montadas com uma categorização ampla e autônoma que incluía as expectativas e atitudes dos entrevistados em relação à atenção farmacêutica. Em seguida, os temas que foram ajustados nessas categorias, foram reagrupados em subcategorias mais limitados e detalhados. A categorização final que emergiu desse processo incluiu parte da codificação a priori elaborada para o roteiro de entrevistas e elementos surgidos durante as entrevistas. Os resultados dos grupos de focais estão nos anexos A, B, C e D. 


\section{RESULTADOS DOS GRUPOS FOCAIS}

O Anexo A apresenta as motivações e grupos de referência dos entrevistados para demandarem a assistência à saúde. As motivações incluem as doenças mais diversas. Percebe-se a existência de doenças mais específicas para os idosos e outras mais específicas para os mais jovens. Além disso, os profissionais da área de saúde, as mulheres jovens adultas e os estudantes de ensino médio noturno indicaram como motivações, para se buscar um serviço de saúde, a procura por métodos contraceptivos e os problemas relacionados à droga, ao álcool e à depressão.

Apesar de também serem alunos do ensino médio, os estudantes do período diurno não citaram essas motivações para ida a um serviço de saúde. O que mais chamou atenção, nesse grupo, foi a presença da mãe na tomada de decisão, que assume os papéis de influenciadora da compra, compradora e pagadora dos produtos e serviços farmacêuticos, além de ser a promovedora da adesão ao tratamento. Até mesmo as mulheres da terceira idade recordaram-se das mães como indicadoras de medicamentos e ervas medicinais. Provavelmente existe uma associação entre a figura da mãe e a saúde. Ao contrário dos estudantes do ensino médio diurno, os estudantes do ensino médio noturno procuram se afastar da influência dos pais, pois, segundo eles, causam inibições e não gostariam que soubessem sobre sua vida sexual ou de problemas como o uso de drogas e álcool.

O Anexo B mostra a atitude dos entrevistados em relação ao conceito "serviço de atenção farmacêutica". Os entrevistados, a exceção da profissional de farmácia que atende no posto de saúde do bairro, desconhecem a existência de serviços de atenção farmacêutica e sua operacionalização, por conseguinte, não sabem caracterizá-lo em termos de oferta, benefícios, ambiente em que é realizado nem mesmo quem o realiza. Sobre esse último ponto, percebeu-se que a falta de conhecimento não é apenas sobre a atenção farmacêutica ou quem deve praticá-la. Os grupos de entrevistados deixaram claro que não entendiam o papel do farmacêutico, ou seja, o seu trabalho nem a sua função. Em muitos momentos, ele foi comparado ao balconista da farmácia. Em outras situações, os entrevistados classificavam 
o farmacêutico como sendo um "médico que não passa a receita", mas que indica muitos medicamentos e, às vezes, é melhor que o médico.

No entanto, após ser explicado por meio de um vídeo, os entrevistados externaram um sentimento de simpatia em relação ao serviço de atenção farmacêutica, exceção feita ao grupo de jovens mulheres, para algumas delas, o serviço poderia tomar muito tempo, atrapalhando as suas atividades profissionais e domésticas. Em relação à necessidade de uma sala reservada para a realização da atenção farmacêutica, todos os grupos entrevistados verificaram a sua importância, considerando que há situações constrangedoras a exigir privacidade. No entanto, algumas mulheres jovens mencionaram que o atendimento no balcão da farmácia poderia ser mais rápido.

Vale destacar a preocupação dos profissionais de saúde e dos estudantes de ensino médio noturno em preservarem seus problemas do conhecimento do público em geral, e em especial, dos pais, pois tinham receio de que estes conhecessem suas práticas sexuais. Os profissionais de saúde caracterizaram esse fato pelo medo de serem "delatados", indicando que muitos preferem ir ao posto de saúde desacompanhados.

O Anexo C trata das expectativas do público entrevistado para com os serviços de atenção farmacêutica a ser ofertado pela UFVS por meio da sua farmácia universitária. Os entrevistados entenderam que qualquer pessoa faz parte do público-alvo da atenção farmacêutica. No entanto, dois grupos se destacaram nas respostas: os idosos e as pessoas mais carentes. As jovens mulheres se excluíram desse público, pois alegaram que "não têm tempo para conversar na farmácia."

Foi observado durante as entrevistas um descontentamento muito grande com o atendimento recebido de balconistas e farmacêuticos de farmácias da rede privada, assim como de médicos e demais profissionais de saúde. Talvez, por esse motivo, a expectativa dos entrevistados com a atenção farmacêutica da UFVS seja alta, visto esperarem atenção, carinho, acolhimento, explicações detalhadas referentes aos problemas de saúde e um tempo maior dedicado ao atendimento, além da oferta de um bom preço e qualidade. 
Os entrevistados também aguardavam que a prestação do serviço fique a cargo de estudantes, supervisionados por profissionais formados, ou dos próprios farmacêuticos da UFVS. Contudo, não descartaram a possibilidade de que outros profissionais de saúde participassem do programa, tais como: médico (mais citado), psicóloga e assistente social. Em relação ao horário de atendimento, os entrevistados preferiram que fosse durante o dia. No entanto, as jovens adultas, que se caracterizam por mulheres que trabalham durante o dia, recomendaram que o atendimento fosse também à noite de $18 \mathrm{~h}$ às $22 \mathrm{~h}$. A imagem formada para o serviço inclui salas com cores claras, organizadas, climatizadas e bem iluminadas.

Quanto à precificação, os entrevistados observaram que "quanto mais barato o serviço, pior a sua qualidade". Por isso, houve sugestões de até $\mathrm{R} \$ 50,00$ por meia hora de consulta. No entanto, todos sinalizaram que os serviços poderiam ser gratuitos, pois entendem que uma parte grande do público não poderia pagar. No quesito preço, foram dadas como sugestões precificar os medicamentos num valor mais elevado para cobrir as despesas com a atenção farmacêutica e com os demais profissionais de saúde da farmácia e a possibilidade de pagamento por crediário.

Os entrevistados confiam no serviço de atenção farmacêutica da farmácia universitária da UFVS apresentando sentimentos positivos em relação a este. Essa boa expectativa é decorrente do fato de esperarem que as visitas domiciliares auxiliem os idosos na adesão ao tratamento. De acordo com os grupos focais, os idosos teriam dificuldades para a leitura e memorização da ordem de aplicação dos medicamentos durante o tratamento, o que comprometeria a adesão terapêutica. Portanto, a expectativa de ter alguém para auxiliar os idosos na organização do uso da medicação foi considerada extremamente válida, além de contribuir para o acesso das comunidades carentes aos medicamentos.

No Anexo D estão anotadas as sugestões dos entrevistados, as quais foram agrupadas em sugestões gerais e sugestões de meios de comunicação pelos quais o serviço poderia ser divulgado. As primeiras incluíam a oferta de produtos de conveniência, "produtos de uma farmácia verde", estacionamento, parcelamento do pagamento e ampla diversidade de me- 
dicamentos. O serviço de entrega de medicamentos foi sugerido para proporcionar o acesso facilitado do cliente ao medicamento, uma vez que as distâncias no bairro são extensas.

Para divulgar o serviço de atenção farmacêutica, sugeriu-se utilizar carro de som, programas de rádio (Programa do Seu Zé, que ocorre às 17h) e TV (programa do Noberto), jornal e panfleto, e indicação de profissionais de área de saúde para referendar o serviço, como, por exemplo, membros do conselho de saúde.

\section{OS PRÓXIMOS PASSOS}

Patrícia formulou novas questões ao reler o relatório final dos grupos focais: Qual deveria ser o posicionamento do serviço de atenção farmacêutica? Como o ambiente deveria ser organizado? Como seria a atuação dos estagiários? Qual estratégia de comunicação de marketing seguir? O serviço deveria ser cobrado? Álvaro havia adiantado que, na reunião seguinte, essas questões seriam debatidas para a conclusão do plano de negócios da farmácia. Ele estava bastante entusiasmado diante do resultado dos grupos focais, pois haviam levantado informações relevantes para o planejamento estratégico e tático da farmácia. 


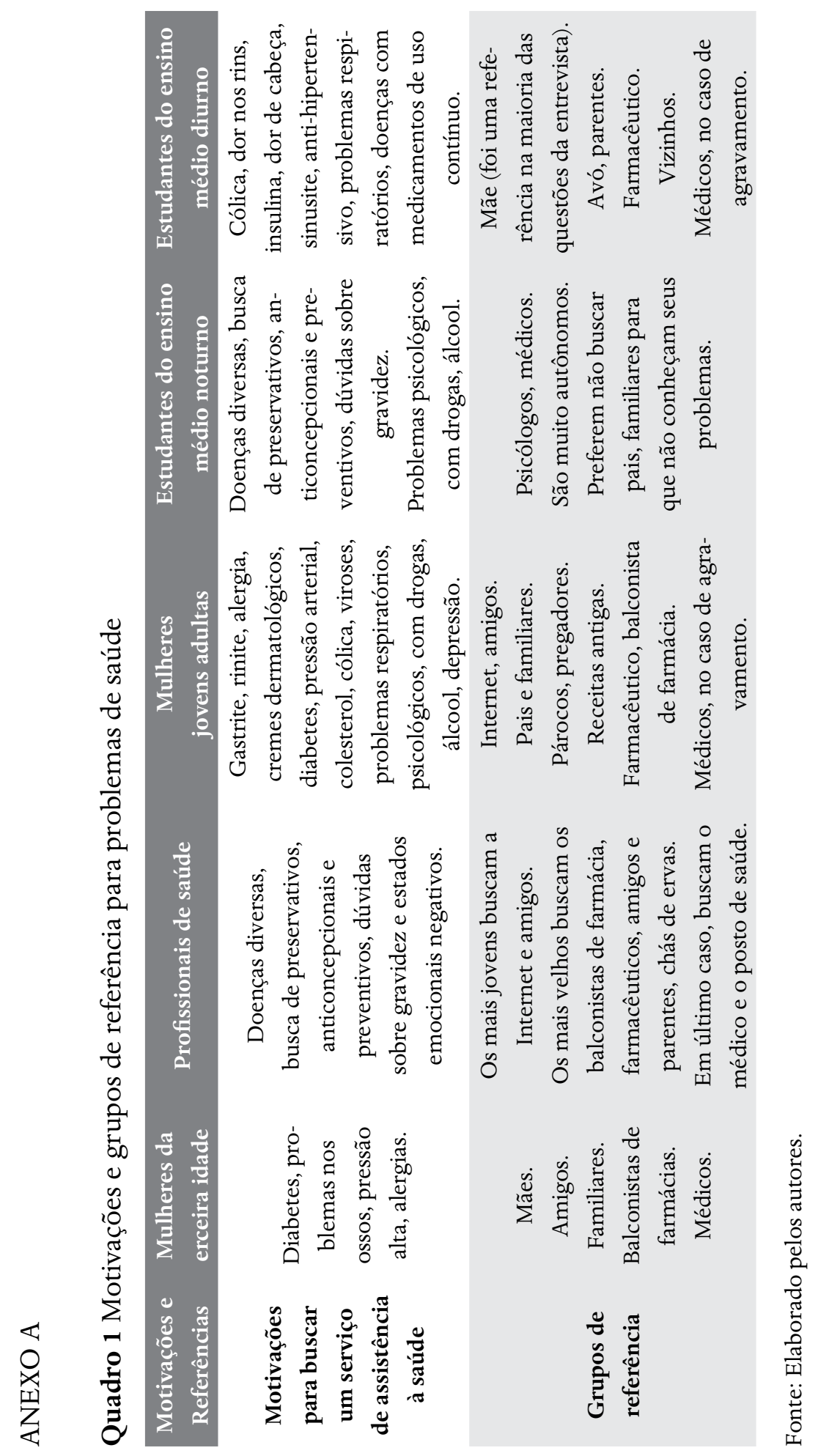




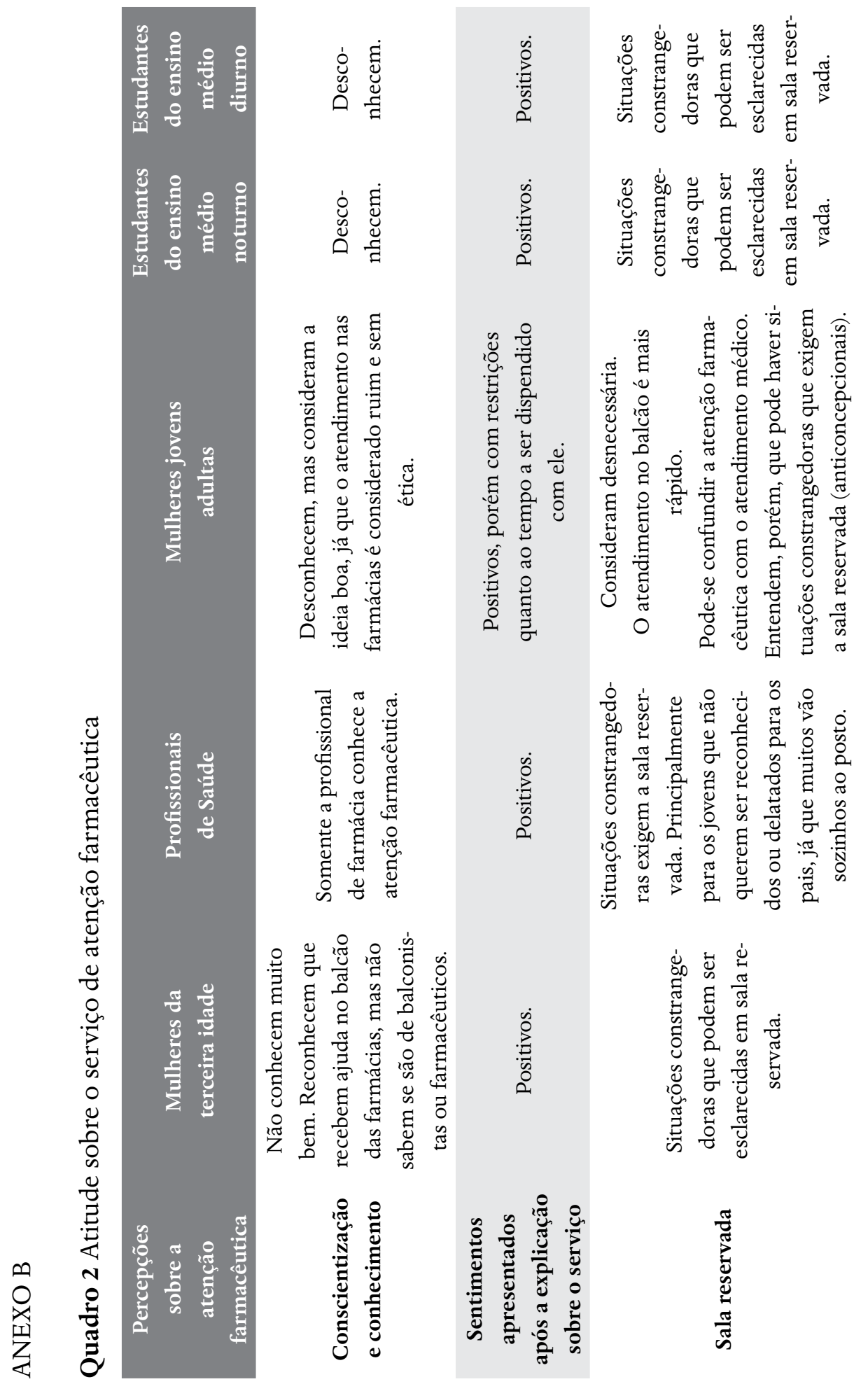

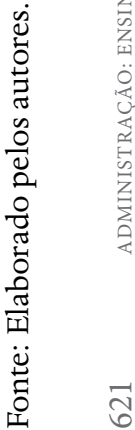




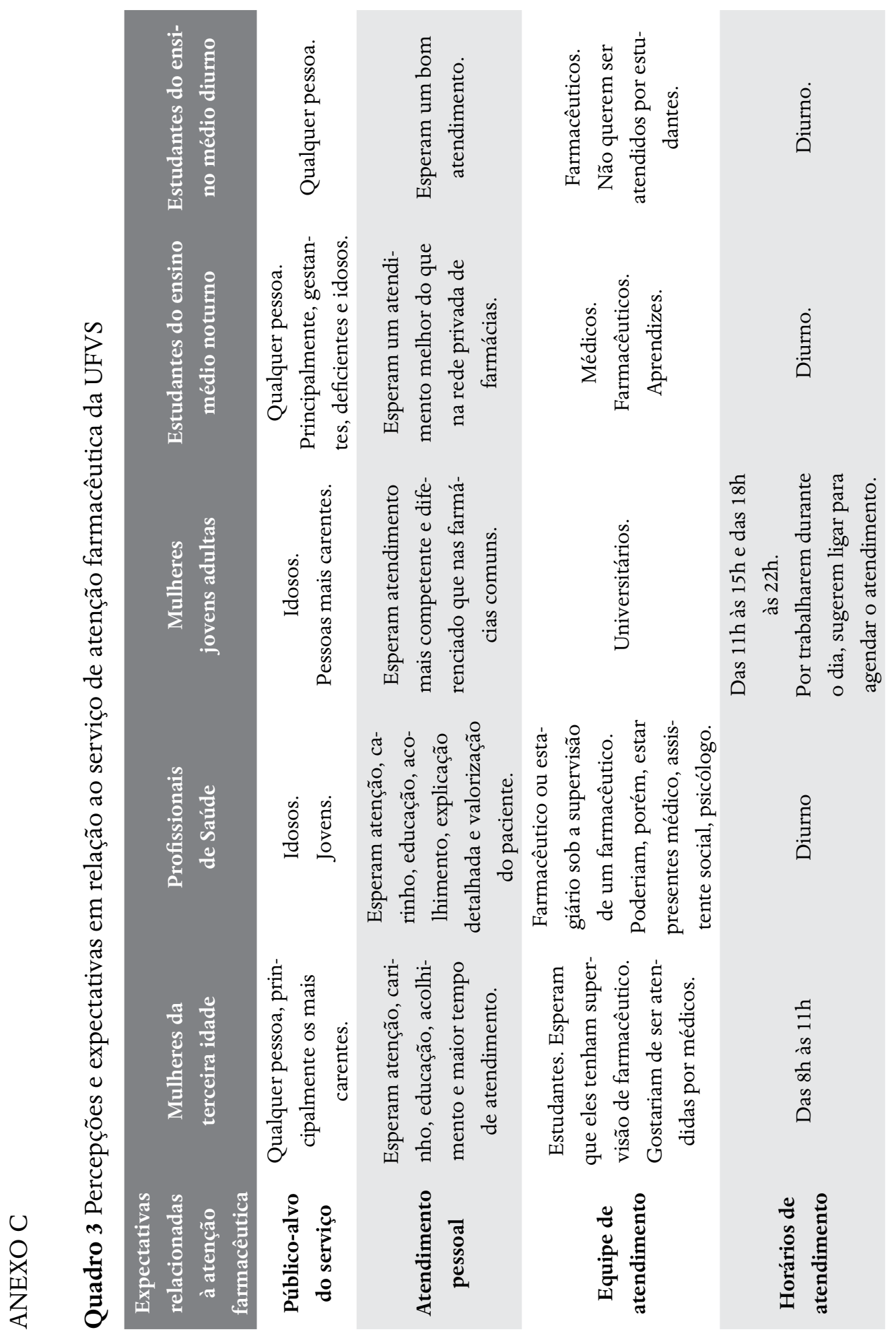



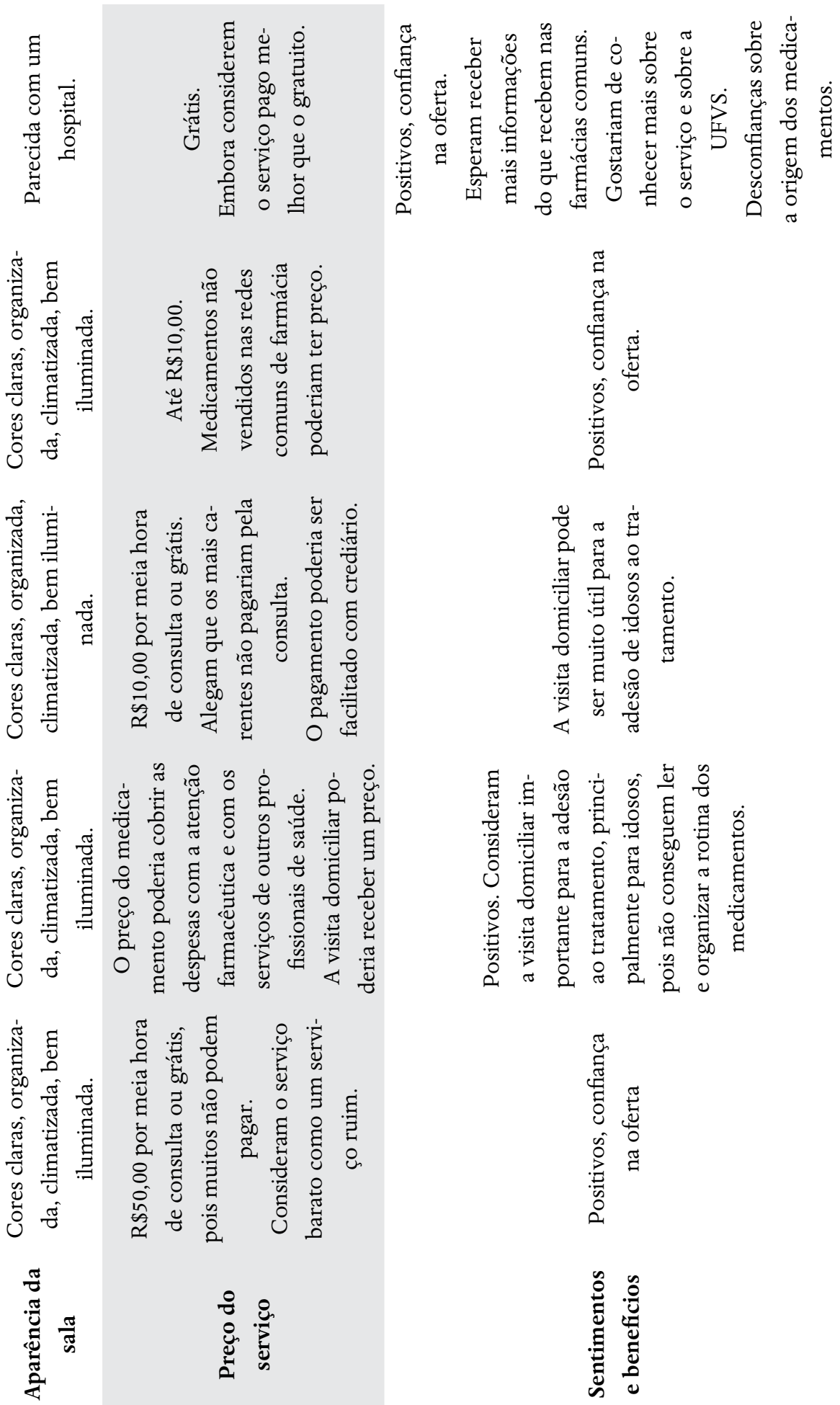


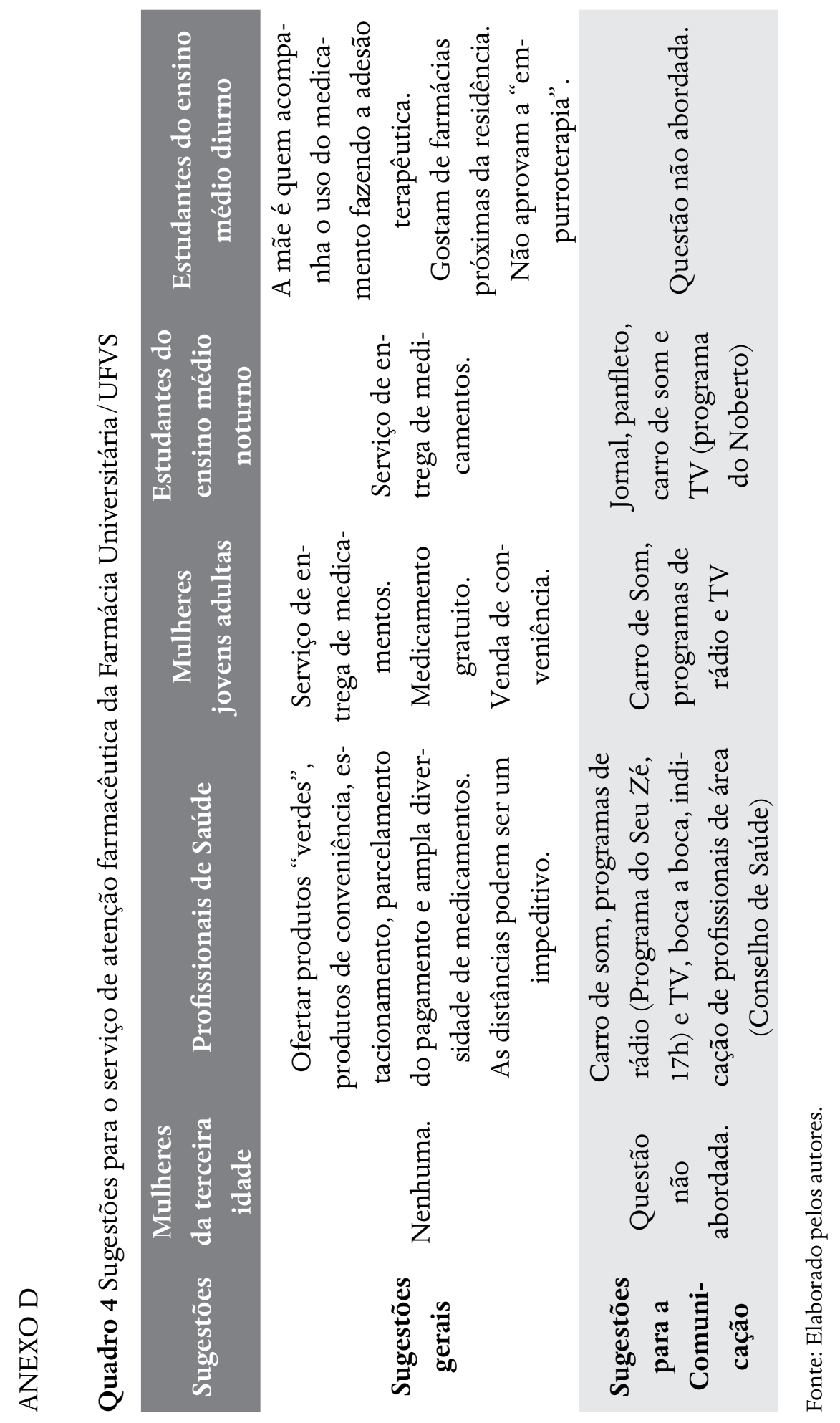




\section{NOTAS DE ENSINO}

\section{OBJETIVOS EDUCACIONAIS}

Este caso retrata, portanto, o empenho de um grupo de professores para montar uma farmácia universitária. Durante a leitura, o aluno é paulatinamente inserido na perspectiva da coordenadora do curso de farmácia que caminha junto de sua equipe na firme proposta de abrir o estabelecimento tendo por base a oferta do serviço de atenção farmacêutica. Dada a riqueza das informações apresentadas, ele possui quatro objetivos:

- Primeiro, localizar o aluno na perspectiva da coordenadora e convidá-lo a desenvolver alternativas de posicionamento para o serviço de atenção farmacêutica;

- Segundo, para cada alternativa de posicionamento, desenvolver uma solução de gestão de marketing de serviços contemplando as evidências físicas, de pessoas, processos, comunicação de marketing e apreçamento;

- Terceiro, analisar os grupos focais realizados, propondo soluções alternativas para os procedimentos passíveis de crítica;

- Quarto, interpretar o caso de acordo com os princípios da Lógica Serviço-dominante.

\section{UTILIZAÇÃO RECOMENDADA}

Trata-se de um caso real cujos nomes de pessoas e instituições foram alterados para preservação de suas identidades, cuja aplicabilidade ajusta-se às disciplinas de Marketing, Marketing de Serviços, Pesquisa de Marketing, Comportamento do Consumidor. Pode ser discutido por alunos da graduação e de pós-graduação de Administração.

\section{FONTES DE DADOS}

O caso foi elaborado a partir de informações obtidas mediante observação participante. Os autores do caso participaram dos grupos focais organizados para secundar o planejamento da farmácia, cuja constituição englobou clientes de farmácias e drogarias, pacientes com doenças crô- 
nicas e idosos. Além disso, estes participaram de entrevistas semiestruturadas com proprietários de farmácias, médicos e outros profissionais de saúde. Também foram consultadas as resoluções do Conselho Federal de Farmácia e realizada uma visita técnica à farmácia universitária de um campus universitário.

\section{SUGESTÕES PARA O PREPARO DA AULA}

O método do caso emprega a aprendizagem autoorientada que faz uso de análise para extrair conclusões sobre uma dada situação (ELLET, 2008). A análise pressupõe a separação de um todo em seus elementos componentes e o estudo das partes com o todo. Para analisar um caso, portanto, é preciso compreender os aspectos importantes de uma dada situação e o que significam em relação à situação como um todo.

A análise deve ser empreendida sob a perspectiva de uma base teórica. Sem essa fundamentação, o aluno terá dificuldades de identificar e entender as situações relevantes. O professor deve indicar o referencial teórico pertinente ao assunto que ele deseja extrair do caso. Por isso, recomenda-se que o aluno vá para a discussão preparado com a leitura prévia do referencial teórico indicado pelo professor. As referências ao final da nota são indicações de leitura prévia para a preparação do caso.

Apesar dos casos poderem apresentar os mais diferentes objetivos, didaticamente, são agrupados em quatro (ELLET, 2008), a saber: apresentação de problemas, indicação de decisões, proposição de avaliações e análise de regras.

O caso Atenção farmacêutica: nem só de medicamento vive uma farmácia é um caso organizado em torno de uma decisão explícita, mas também oferece a oportunidade para a indicação de problemas e a realização de análises. A decisão explícita aparece quando Patrícia reflete que deve tomar decisões necessárias à abertura da farmácia universitária. Quaisquer que sejam as dimensões dessas decisões, os alunos deverão apresentar as suas opções, elaborar um critério de decisão e enumerar as evidências relevantes para suas escolhas. A indicação de problemas e as análises surgem quando se propõe que o aluno faça uma crítica ao uso do grupo focal e interprete o 
caso sob a lente da Lógica Serviço-dominante. Contudo, mesmo nessas situações, o discente é chamado a propor soluções e abordagens alternativas para os problemas identificados e as interpretações realizadas.

Assim, a proposta para a dinâmica de discussão do caso, considerando uma aula de 120 minutos, é a seguinte:

Etapa 1 - Preparação prévia individual antes da aula.

$\checkmark$ Leitura prévia do referencial teórico recomendado pelo professor;

$\checkmark$ Leitura do caso individualmente e estabelecimento de problemas e decisões.

Etapa 2 - Discussão em grupo em aula

$\checkmark$ Resumir o caso com a participação da turma para certificar-se de que todos o compreenderam (10 minutos);

$\checkmark$ Listar os principais pontos do caso na lousa: personagens, problemas, situações relevantes para a tomada de decisão (10 minutos);

$\checkmark$ Divisão da turma em grupos para a discussão das questões propostas para a análise do caso;

$\checkmark$ Os grupos devem responder às questões propostas para a discussão, identificando problemas e estabelecendo as soluções possíveis e seus critérios de escolha. Os grupos devem traçar os pontos positivos e negativos de suas opções (20 minutos).

Etapa 3 - Discussão em classe

$\checkmark$ Os grupos devem apresentar os problemas, opções de decisão e critérios de escolha para cada questão proposta. (30 minutos);

$\checkmark$ O professor deve listar os problemas, as opções e os critérios de decisão no quadro. Os pontos positivos e negativos devem ser considerados durante a discussão; 
$\checkmark$ O professor deve estimular a reflexão teórica que fundamenta as decisões e os critérios de escolha;

$\checkmark$ O professor deve não só escolher com a turma uma decisão e recomendar um plano de ação para esta, bem como deve lembrar que o objetivo do estudo de caso não é encontrar uma decisão certa para o caso ou alcançar o consenso, mas avaliar diferentes opções embasadas no conteúdo disciplinar. O caso de ensino é um recurso didático (30 minutos).

Etapa 4 - Encerramento (10 minutos)

$\checkmark$ O professor faz uma breve exposição final e realiza um balanço das inúmeras possibilidades que o curso de farmácia teria a adotar;

$\checkmark$ O professor deve abordar ainda as possibilidades não pensadas pelos grupos e verificar se alguém tem mais alguma sugestão.

\section{QUESTÕES PARA DISCUSSÃO E RELAÇÕES COM A LITERATURA}

As questões para discussão têm por objetivo promover a reflexão dos estudantes a fim de que o caso seja analisado e interpretado de acordo com os conceitos de posicionamento da oferta, marketing de serviços, grupos focais e lógica serviço-dominante. A seguir são apresentadas as questões com suas respectivas sugestões de respostas, as quais foram formuladas tendo por referência a literatura consultada.

1. Ao final do caso, a equipe de planejamento da farmácia universitária tem à sua frente muitas decisões a tomar. Estabeleça uma declaração de posicionamento para o serviço de atenção farmacêutica e desenvolva uma estratégia de marketing de serviços para o seu lançamento. Conforme descrito no caso, considere que a localização da farmácia já foi dada e o serviço de atenção farmacêutica não envolve a venda de nenhum produto. 


\section{POSICIONAMENTO}

A estratégia de posicionamento distingue uma marca de suas concorrentes e é um guia para a estratégia organizacional (LOVELOCK; WIRTZ; HEMZO, 2011), refere-se à percepção que a organização deseja que um ou mais grupos-alvo tenham com relação aos benefícios proporcionados pela sua oferta, comparativamente às dos concorrentes. Por isso, o posicionamento deve ter significado para os clientes, ser viável em relação às competências da organização e ser sustentável em relação à concorrência. Trata-se de um compromisso com o público-alvo, e uma vez ocupado um espaço na sua mente, não é fácil mudar de posição.

Quatro questões orientam a definição de posicionamento (ROCHA; FERREIRA; SILVA, 2012): que tipo de oferta a empresa apresenta ao mercado e quais os benefícios proporcionados por ela? Qual o grupo-alvo será atendido pela oferta e quais as características principais desse grupo que são relevantes para a adoção do produto ou serviço? Em relação aos concorrentes, quais as credenciais da empresa/produto/serviço/marca que lhe permitem atender melhor às necessidades do cliente? Quais os motivos para o cliente confiar nas promessas que a empresa/produto/serviço/marca lhe faz?

A declaração de posicionamento é um parágrafo que sumariza o posicionamento desejado para a oferta (ROCHA; FERREIRA; SILVA, 2012) e reúne os elementos indicados nas questões que orientam a definição do posicionamento. A partir disso, é proposta a seguinte declaração de posicionamento: "A atenção farmacêutica da UFVS (Oferta) é um serviço ofertado exclusivamente por experientes profissionais (Atestado de confiabilidade) capacitados no Curso de Farmácia da melhor universidade federal da região (Comparação com a concorrência) que levam acolhimento às pessoas que estão em tratamento médico (Público-alvo) para recuperação da sua saúde por meio do uso adequado de medicamentos (Benefícios)”.

\section{ESTRATÉGIA DE MARKETING DE SERVIÇOS}

As interações de serviços envolvem pessoas, recursos físicos, informações, sistemas e infraestruturas que entrando em operação têm a finalidade de encontrar uma solução para o problema do cliente. Como coprodutor, o 
cliente influencia o progresso de produção do seu serviço opinando sobre resultados e recursos utilizados, a sua interação pode ser remota ou direta com o prestador de serviços, e a presença de outros clientes podem auxiliá-lo, gerando ou ampliando a sua satisfação. Assim, quando se planeja o marketing de serviços, tem-se de ir além das decisões de produto, preço, comunicação e localização. As características singulares dos serviços impõem ao seu planejamento de marketing reflexões a respeito de pessoas, evidências físicas e processo do serviço (ZEITHAML; BITNER; GREMLER, 2014).

Como a venda de medicamentos e a localização já estavam equacionadas, as sugestões a seguir abordam as decisões sobre evidências físicas, pessoas, processo, comunicação e apreçamento.

\section{EVIDÊNCIAS FÍSICAS}

As evidências físicas empacotam o serviço dando-lhe tangibilidade e promovendo a interação social entre clientes e prestadores de serviços. Um bom conjunto de evidências físicas favorece a avaliação da qualidade dos serviços. As entrevistas realizadas sinalizaram a importância de se criar um ambiente organizado, claro e climatizado. Esse ambiente favorecerá a socialização e o controle da demanda, portanto, deve-se prever a presença de assento e televisão para espera. Para ofertar a atenção farmacêutica, sugere-se a instalação de uma sala reservada, pois contribui para a geração da confiança do cliente, uma vez que garantirá sua privacidade.

A marca é uma evidência física relevante em serviços, pois expressa em seu planejamento os benefícios da oferta e proporciona laços afetivos e benefícios emocionais para o usuário do serviço. Essas conexões emocionais exigem uma sintonia de valores entre a marca e seu usuário. Portanto, ao se posicionar uma marca, devem-se considerar os atributos, os beneficios, as crenças, os valores e a cultura que deve refletir que serão traduzidos em cores, formas, fontes, elementos, símbolos, ícones e suas formas de aplicações.

Os grupos focais revelaram certo distanciamento dos profissionais de saúde, notadamente os médicos, na atenção primária à saúde. O público espera ser valorizado, sendo atendido com atenção e acolhimento. A marca 
da farmácia universitária pode incorporar essa demanda em seu projeto, refletindo os benefícios emocionais almejados por seu público, o que certamente fortalecerá os vínculos afetivos entre ambos.

\section{GESTÃO DE PESSOAS}

No que se refere à gestão de pessoas, deve ser considerada a definição do papel do prestador de serviços e da equipe de contato. Uma vez que os entrevistados revelaram forte desapontamento com o atendimento na saúde, recomenda-se que os profissionais e estagiários sejam selecionados, considerando a necessidade de uma atitude favorável ao acolhimento e à atenção ao cliente que chega à farmácia. Portanto, embora competências e habilidades sejam necessárias, não são os únicos quesitos a serem trabalhados. Se essa seleção não for possível, recomenda-se um trabalho de treinamento comportamental, no esforço de desenvolver uma atitude mais humanizada.

O tratamento mais humanitário pode fazer com que os pacientes formem vínculos com os profissionais da farmácia. Isso representa um fator positivo, uma vez que os vínculos fortalecem a confiança e a segurança em relação ao serviço prestado, algo essencial para garantir a qualidade dos serviços (ZEITHAML; BITNER; GREMLER, 2014). No entanto, a rotatividade dos estagiários pode ser um componente a gerar insegurança $\mathrm{e}$ desconfiança nos pacientes, porquanto compromete a formação dos vínculos, prejudicando o relacionamento dos pacientes com a farmácia. Neste sentido, o treinamento dos estagiários contribui para garantir um padrão no atendimento, de forma a minorar os efeitos da rotatividade.

\section{PROCESSOS DE SERVIÇOS}

Em relação aos processos de serviços, as sugestões dos entrevistados podem auxiliar a organizar a entrega do serviço, evitando a formação de filas e esperas. Essas sugestões incluem o agendamento do serviço de atenção farmacêutica, disponibilidade para o atendimento domiciliar e espaço para estacionamento. Desse modo, as pessoas com dificuldades de locomoção e/ou com limitações de horários têm uma alternativa de atendimento. 
Outra opção refer-se ao estabelecimento de um canal de comunicação via telefone, whatsapp, ou mesmo em outras redes sociais para que os pacientes expressem suas dúvidas quando não puderem ir à farmácia.

\section{COMUNICAÇÃO DE MARKETING}

Observa-se nos entrevistados um desconhecimento em relação ao que seja pertinente às atividades do profissional de farmácia, ou seja, do farmacêutico e, por consequência, há o desconhecimento do que seja a atividade de atenção farmacêutica. Assim, a comunicação de marketing tem duas propostas cognitivas, em que a primeira é esclarecer à população do bairro Santa Isabel sobre a atividade de atenção farmacêutica e quem está apto a realizá-la. A segunda, a comunicação deve divulgar a oferta do serviço de atenção farmacêutica. Diante disso, a comunicação de marketing terá como objetivos: conscientizar o público-alvo da farmácia para o conhecimento do que seja a atenção farmacêutica, quem pode realizá-la e divulgar a oferta desse serviço.

Nas entrevistas, ficou evidente a importância dos serviços de saúde para os idosos e pessoas mais carentes. Assim, as peças de comunicação de marketing devem se dirigir, preferencialmente, a esse público. O composto promocional é formado por propaganda, promoção de vendas, marketing direto, venda pessoal e relações públicas. No caso em estudo, recomenda-se utilizar a propaganda em mídia não iterativa de massa, adotando as sugestões dos entrevistados: carro de som, programas de rádio (Programa do Seu Zé, que ocorre às 17h) e TV (programa do Noberto).

Outra ferramenta a ser utilizada são as atividades de relações públicas tendo em vista que se observou forte interação social nos grupos de entrevistados, recomenda-se montar eventos que promovam essa interação, enquanto divulgam o serviço de atenção farmacêutica e a marca da farmácia universitária, sob a chancela da UFVS.

Verificou-se acentuada influência dos grupos de referência quando o assunto é o binômio saúde/doença, os quais incluem especialmente familiares, amigos, vizinhos, sítios eletrônicos e balconistas de farmácias. Suas indicações abordam tratamentos, medicamentos, médicos e farmácias. 
Convém salientar a figura da mãe como formadora de opinião na família, tanto para os estudantes do ensino médio diurno quanto para as mulheres da terceira idade, grupos que devem ser aproveitados no contexto das mensagens. Suas presenças como emissores das mensagens contribuirão para a credibilidade da farmácia universitária.

Quanto ao estilo das mensagens, sugere-se que exibam cenas da vida real e evidências científicas. Uma cena da vida real, como o próprio nome diz evoca as cenas do cotidiano, enquanto que as evidências científicas recorrem a um profissional de saúde para dar credibilidade ao objeto da divulgação. Os membros do Conselho Municipal de Saúde foram indicados para referendar a farmácia universitária.

\section{APREÇAMENTO}

A definição do preço deve contemplar a percepção da demanda e os custos da oferta do serviço, inclusive se a consulta for ofertada ao preço zero, o cálculo do custo ainda é relevante para computar o montante dos subsídios necessários para suportar esse preço.

Os custos podem ser diretos e indiretos, os primeiros relacionam-se aos custos apropriados diretamente aos serviços produzidos, incluem salários dos funcionários (salário, encargos, férias e $13^{\circ}$ ), bolsas estudantis, materiais de consumo, como descartáveis, suprimentos de informática, toalha e papel higiênico. Já os custos indiretos relacionam-se àqueles cuja medida não está alocada diretamente à produção do serviço, necessitando de estimativas e rateios, compreendem: aluguel, telefone, água, energia elétrica, manutenção, serviço de limpeza, incluindo os salários pagos nesses serviços. A Tabela 1 apresenta uma estimativa dos custos mensais. 


\section{\& MARLUSA GOSLING}

Tabela 1 Estimativa de custos mensais

\begin{tabular}{rlrr} 
& \multicolumn{1}{c}{ Item } & Custo Estimado \\
\multirow{2}{*}{ Indiretos } & Aluguel & & $\mathrm{R} \$ 1.024,00$ \\
& Telefone, água, manutenção e limpeza & $\mathrm{R} \$ 405,61$ \\
& Energia Elétrica & Subtotal & $\mathbf{R} \$ \mathbf{1 . 5 0 2 , 0 6}$ \\
\multirow{2}{*}{ Diretos } & Salários & & $\mathrm{R} \$ 16.146,14$ \\
& Materiais de consumo & & $\mathrm{R} \$ 203,00$ \\
& & Subtotal & $\mathbf{R} \mathbf{1 6 . 3 4 9 , 1 4}$ \\
& & Total & $\mathbf{R} \mathbf{1 7 . 8 5 1 , 2 0}$ \\
\hline
\end{tabular}

Fonte: Elaborado pelos autores.

A partir desse quadro, pode-se estimar o valor médio de 1 hora de atendimento no serviço de atenção farmacêutica. Considerando-se 240 horas trabalhadas no mês para todos os funcionários e bolsista, o custo de uma hora de consulta farmacêutica será $\mathrm{R} \$ 74,38$. Esse valor sinaliza a relevância do subsídio e da formação de parcerias, uma vez que extrapola os valores sugeridos pela demanda. Assim, se a consulta não for cobrada, o subsídio corresponderá ao valor integral dos custos. Se for cobrado o valor sugerido pelos entrevistados (de $\mathrm{R} \$ 10,00$ a $\mathrm{R} \$ 50,00$ ), o valor do subsídio será menor proporcionalmente.

Para decidir sobre o valor final da consulta, tem de se ter em consideração algumas variáveis como o perfil do público-alvo, o posicionamento adotado para o serviço e o papel da universidade pública na promoção social. Muitos serviços públicos cobram taxas para a sua manutenção. Além disso, "aquilo que é de graça não tem qualidade". Portanto, sugere-se que seja cobrado um valor simbólico pela consulta, talvez $\mathrm{R} \$ 20,00$, mas que seja informado em placa convenientemente fixada uma descrição dos custos totais do serviço para que o usuário saiba como os recursos públicos estão sendo utilizados. 
2. O grupo de planejamento da farmácia universitária realizou pesquisas com grupos focais para analisar as atitudes, motivações e expectativas do público-alvo sobre o lançamento do serviço de atenção farmacêutica. Avalie as condições de uso e vantagens da aplicação dos grupos focais no caso em questão e verifique se outra técnica de pesquisa poderia ter sido utilizada em sua substituição ou complementarmente ao seu emprego.

No estudo de serviços os grupos focais são amplamente utilizados para conhecer as dimensões da qualidade em serviços, motivações, atitudes, preferências dos consumidores, percepções sobre novos serviços, e para fundamentar a seleção de participantes para entrevistas em profundidade (ZEITHAML; BITNER; GREMLER, 2014). Representam um tipo de entrevista em profundidade que podem anteceder estudos quantitativos ou ser utilizado juntamente com outros métodos qualitativos (BARBOUR, 2009). Antecedendo a estudos quantitativos, auxiliam a desenvolver hipóteses, definir palavras a serem utilizadas em escalas de questionários estruturados e a sondar o balanceamento de escalas. Na pesquisa qualitativa, colaboram com o pesquisador no desenvolvimento de conceitos e entendimento sobre o tema, as dimensões de qualidade em serviços, as atitudes e preferências dos consumidores.

Ribeiro e Newmann (2006) apresentam extensa lista de verificação para auxiliar o planejamento de grupos focais, que inclui reflexões acerca da elaboração e aplicação do roteiro de entrevistas, número de participantes, organização da sala, mobiliário, equipamentos e recursos a serem utilizados para o registro das entrevistas. Na definição do número de elementos do grupo focal, busca-se a homogeneidade dentro do grupo num dado contexto de vida socioeconômico e demográfico. Grupos homogêneos de 8 a 12 pessoas garantem um debate dinâmico e natural (MALHOTRA, 2006). O número de grupos focais que devem ser feitos depende das comparações desejadas pelo pesquisador (BARBOUR, 2009), da natureza do problema, do número de segmentos distintos de mercado, do número de novas ideias geradas por cada grupo sucessivo e do tempo e custo (MALHOTRA, 2006). 
Antecedendo à abertura da farmácia universitária, os grupos focais realizados conseguiram reunir informações relacionadas à percepção do público acerca do serviço de atenção farmacêutica. No entanto, alguns problemas do uso do método de pesquisa colocam em dúvida a qualidade dos resultados. Inicialmente se observa que os grupos foram muito distintos uns dos outros e, portanto, conseguiu-se certa diversidade de opiniões entre os grupos. No entanto, não se pode afirmar que houve saturação nas respostas, na medida em que se progredia de um grupo focal para outro. Isso porque foram realizados cinco grupos focais, todos com homogeneidade interna, no enanto, muito heterogêneos entre si. Logo, depreende-se que nem todas as respostas progrediram para um padrão.

Tal situação leva ao problema de generalização dos resultados. Uma forma de se conseguir alguma generalização é por intermédio da maneira como a seleção dos componentes é feita e pela comparação sistemática dos dados coletados (FLICK, 2009). Desse modo, torna-se possível replicar as características e contextos dos grupos pesquisados, obtendo codificações que caminham para uma tipologia. Considerando que o público-alvo da farmácia é predominante de mulheres, os grupos focais deveriam ser também predominantemente femininos e internamente homogêneos. Assim, a sucessão de entrevistas geraria respostas que caminhariam para um padrão cada vez com menos novidades até que o tema fosse esgotado. Esse procedimento proporcionaria confiabilidade nos resultados.

No entanto, não foi isso que ocorreu. Houve apenas dois grupos formados por mulheres, dos quais um deles era formado por mulheres da terceira idade e o outro formado por mulheres jovens interessadas nos problemas relacionados à saúde e aos vícios. Outros grupos femininos poderiam ter sido formados para se captar a diversidade de opiniões das mulheres do bairro. Por exemplo, um grupo formado por mulheres com filhos na primeira infância e outro formado por mulheres com filhos adolescentes, ou mulheres que trabalham fora e mulheres que trabalham nos serviços domésticos de suas próprias residências.

Uma forma de obter a confiabilidade é por meio da triangulação de dados, de métodos ou de investigador no estudo do mesmo problema de 
pesquisa (FLICK, 2009). A triangulação de dados refere-se ao uso de diferentes fontes de dados; a triangulação metodológica diz respeito ao uso de diferentes métodos de pesquisa enquanto a triangulação do investigador é o emprego de diferentes pesquisadores na abordagem da aplicação do método de pesquisa e na análise dos seus resultados.

De certa forma, a professora Selena aplicou a triangulação de dados quando utilizou grupos heterogêneos nas entrevistas, notadamente aquele formado por profissionais da área da saúde. No entanto, houve problemas na replicação dos grupos, conforme relatado anteriormente. Com relação à replicação de métodos, poderia ter sido adotado também o método do caso e entrevistas em profundidade. O método do caso viabilizaria a aprendizagem mediante casos de sucesso nas redes pública (como o serviço de atenção farmacêutica da Prefeitura de Janaúba/MG) e privada, e a entrevista em profundidade poderia ser conduzida com líderes de opinião do bairro, ou com especialistas no serviço de atenção farmacêutica. Os resultados dessas pesquisas poderiam ser confrontados com os resultados obtidos nos grupos focais, possibilitando confirmar ou fazer descobertas. Por fim, nota-se que quem realizou todo o trabalho dos grupos focais foi a professora Selena, portanto, por mais que quisesse se distanciar do objeto de pesquisa analisado, os resultados da pesquisa apresentam elementos de sua subjetividade. Para evitar a formação desse viés, outros pesquisadores poderiam ter participado da coleta e análise dos dados.

Por permitir o debate e promover a explosão de percepções acerca de um tema de pesquisa, os grupos focais têm sido utilizados preferencialmente a outros métodos de pesquisa, quando o objetivo da investigação consiste em avaliar uma ideia para o lançamento de um novo produto ou serviço. A descrição dos passos seguidos pela professora Selena para realizar as entrevistas deixa claro que a realização de grupos focais é relativamente simples e de baixo custo, quando comparado às surveys, por exemplo. Portanto, suas vantagens são inequívocas.

No entanto, é recomendado que esse esforço de pesquisa seja seguido de um levantamento de campo. As tabelas com os resultados dos grupos focais sinalizam expectativas, atitudes e motivações em relação ao servi- 


\section{\& MARLUSA GOSLING}

ço de atenção farmacêutica que podem ser confirmadas ou não, mediante uma amostragem probabilística proporcionando resultados mais confiáveis, o que dará mais segurança à tomada de decisão da equipe.

3. Essa questão aborda a lógica Serviço-dominante, tema pouco usual entre os pesquisadores brasileiros. Portanto, para respondê-la, o aluno deve compreender os conceitos da lógica Serviço-dominante, lendo previamente os artigos a seguir, disponíveis gratuitamente nas referências indicadas.

JOINER, K. A.; LUSCH, R. F. Evolving to a new service-dominant logic for health care. Innovation and Entrepreneurship in Health, v. 3, p. 25-33, 2016.

VARGO, S. L.; LUSCH, R. F. Institutions and axioms: an extension and update of service-dominant logic. Journal of the Academy of Marketing Science, v. 44, n. 1, p. 5-23, 2016.

A lógica Serviço-dominante concebe o valor como cocriado na interação entre os atores sociais (VARGO; LUSCH, 2016). Dessa forma, as organizações não oferecem valor aos seus clientes, mas sim uma proposta de valor que para ser apropriada necessita do empenho recíproco entre os atores num dado contexto que abarca pessoas, organizações, instituições, informação, tecnologia e bens. Assim, de acordo com a perspectiva da lógica Serviço-dominante, faça uma reflexão acerca da proposta de valor da farmácia universitária e apresente alternativas para a proposição de valor da farmácia.

A cocriação de valor no serviço de saúde exige um grande afinco do paciente para que seja apropriado (SWEENEY; DANAHER; MCCOLL-KENNEDY, 2015), cujo esforço neste sentido movimenta conhecimentos, habilidades e desejos em benefício da sua saúde e bem-estar. Entretanto, esse processo ocorre num determinado contexto, o empenho do paciente se concretiza numa experiência que, além dos aspectos individuais da sua doença, envolve elementos concernentes a sua situação socioeconômica, suas 
crenças culturais e religiosas, seu trabalho, sua família, seus amigos, suas experiências com outros pacientes, dentre outros (JOINER; LUSCH, 2016).

Portanto, para entender a formação da proposta de valor da farmácia universitária pela lente da Lógica Serviço-dominante, é preciso ter em mente que a farmácia universitária não é uma organização que oferece apenas bens e serviços, mas uma organização que participa de uma experiência (VARGO; LUSCH, 2016).

Para se ter uma ideia da amplitude dessa experiência, observa-se que a princípio os atores envolvidos num serviço de atenção farmacêutica seriam o paciente, o farmacêutico, o aluno-aprendiz, e demais profissionais do atendimento da farmácia. No entanto, segundo o depoimento dos entrevistados, adjacentes a estes estão o médico, o fisioterapeuta, o psicólogo e o assistente social do posto de saúde, os quais dão o primeiro atendimento no caso de uma doença. Além destes, foram citados a família, principalmente a mãe, que faz indicações, ministram medicamentos, conferem doses e lembram horários. Outras figuras importantes para os adolescentes da escola pública e as jovens adultas foram os amigos e a Internet, enquanto os primeiros compartilham informações e apoio, cabe a Internet ser provedora de informações, como, por exemplo, nos sítios eletrônicos de bula e blogs de profissionais de saúde e coparticipando experiências por meio de grupos de autoajuda.

A experiência do serviço de saúde pode englobar desde uma consulta, à compra de um medicamento, seu uso, prática da fisioterapia, controle alimentar, e conforme dito pelas jovens mulheres, a adoção de práticas alternativas à medicina convencional, como tratamento com chás e intervenções religiosas de párocos ou pastores. Isso mostra que o contexto das experiências do serviço de saúde extrapola os limites físicos da farmácia. O paciente que ali chega traz consigo uma bagagem de conhecimentos que interfere diretamente na adesão ou mesmo na interrupção do tratamento. Esse contexto não deve ser descartado ao se pensar sobre a experiência de cocriação do valor no serviço de saúde.

Dessa maneira, a oferta da farmácia universitária é apenas uma parte dessa experiência. Para planejar a sua proposição de valor, é preciso refletir 
para além da interação entre paciente e farmacêutico, e lembrar que o valor no serviço de saúde está dentro de um ecossistema de serviço muito mais amplo, cujo processo tem início antes do acesso do paciente à farmácia e se estende para além de suas portas.

Muito embora os profissionais que estejam planejando a farmácia universitária tenham seguido o manual do planejamento estratégico, analisado variáveis do macroambiente e da concorrência e realizado pesquisa de marketing que culminou na proposta do serviço de atenção farmacêutica, nota-se que, nesse processo, não se orientaram pela Lógica Serviço-dominante. Para caminhar nessa direção, deveriam ter pensado a farmácia como um provedor de serviço situado num ecossistema de serviço de saúde, cuja oferta é a saúde, e não apenas serviços isolados como acompanhar o paciente, medir sua pressão, tomar a sua temperatura ou vender um medicamento. A partir dessa premissa, suas escolhas teriam sido direcionadas para ações que culminam na promoção da saúde, mesmo que para isso outros atores sociais, como concorrentes e fornecedores, fossem envolvidos na formulação da oferta da farmácia (VARGO; LUSCH, 2017).

Portanto, seguem algumas alternativas para a proposição de valor da farmácia universitária de acordo com os princípios da Lógica Serviço-dominante:

Primeira, as farmácias e drogarias da cidade já formam uma rede capilar na distribuição de medicamentos e outros produtos. Nesse caso, pode-se pensar no estabelecimento de convênios de estágio com essas farmácias para que os alunos venham a prestar o serviço de atenção farmacêutica em seus estabelecimentos. Isso viabilizaria o serviço de atenção farmacêutica para uma população maior que a do bairro Santa Isabel, contribuindo para a saúde e bem-estar da população.

Segunda, a atenção farmacêutica poderia ser ofertada em parceria com a prefeitura local, levando o atendimento dos estagiários aos postos de saúde da cidade. Essa possibilidade é uma extensão da anterior.

Terceira, na impossibilidade de vender medicamentos industrializados, poderia ser pensada a oferta de medicação alternativa, como a fitoterapia, que não passa pelas restrições de venda das agências de saúde e pode 
ser manipulada no laboratório da universidade. Essa opção está de acordo com os aspectos culturais do grupo de entrevistados que a consideram uma forma de se alcançar a saúde.

Quarta, o serviço de atenção farmacêutica também poderia ser domiciliar, o que facultaria o apoio ao paciente, considerando outras variáveis do seu contexto de vida. Trata-se de um aspecto diretamente relacionado à atenção e ao acolhimento que o grupo de entrevistados espera do serviço de atenção farmacêutica e pode contribuir para a sua cocriação de valor. 


\section{\& MARLUSA GOSLING}

\section{REFERÊNCIAS}

BARBOUR, R. Grupos Focais. Porto Alegre: Artmed, 2009.

ELLET, W. Manual do Estudo de Caso: como ler, discutir e escrever casos de forma persuasiva. Porto Alegre: Bookman, 2008.

FLICK, U. Qualidade na Pesquisa Qualitativa. Porto Alegre: Artmed, 2009.

JOINER, K. A.; LUSCH, R. F. Evolving to a new service-dominant logic for health care. Innovation and Entrepreneurship in Health, v. 3, p. 25-33, 2016.

LOVELOCK, C.; WIRTZ, J.; HEMZO, M. A. Marketing de serviços: pessoas, tecnologia e estratégia. 7. ed. São Paulo: Pearson Prentice Hall, 2011.

MALHOTRA, N. K. Pesquisa de marketing: uma orientação aplicada. 4. ed. Porto Alegre: Bookman, 2006.

RIBEIRO, J. L. D.; NEWMANN, C. R. Estudos qualitativos com o apoio de grupos focados. In: SEMANA DE ENGENHARIA DE PRODUÇÃO SUL-AMERICANA, 13., 2006, Gramado: Anais... Gramado: Seprosul, 2006. p. 1-9.

ROCHA, A.; FERREIRA, J. B.; SILVA, J. F. Administração de Marketing: conceitos, estratégias, aplicações. São Paulo: Atlas, 2012.

SWEENEY, J. C.; DANAHER, T. S.; McCOLL-KENNEDY, J. R. Customer effort in value cocreation activities: improving quality of life and behavioral intentions of health care customers. Journal of Service Research, v. 18, n. 3, p. 318-335, 2015.

VARGO, S. L.; LUSCH, R. F. Institutions and axioms: an extension and update of service-dominant logic. Journal of the Academy of Marketing Science, v. 44, n. 1, p. 5-23, 2016.

VARGO, S. L.; LUSCH, R. F. Service-dominant logic 2025. International Journal of Research in Marketing, v. 34, n. 1, p. 46-67, 2017.

ZEITHAML, V. A.; BITNER, M. J.; GREMLER, D. D. Marketing de serviços: a empresa com foco no cliente. 3. ed. Porto Alegre: M. Education, 2014. 


\section{DADOS DOS AUTORES}

\section{STELA CRISTINA HOTT CORRÊA stelachc@gmail.com}

\section{Mestre em Administração pela COPPEAD-UFRJ}

Instituição de vinculação: Universidade Federal de Juiz de Fora - UFJF

Governador Valadares/MG - Brasil

Áreas de interesse em pesquisa: Comportamento do consumidor; Pesquisa transformativa do serviço; Pesquisa transformativa do consumidor; Destinos turísticos inteligentes.

*Av. Dr. Raimundo Monteiros Rezende, 330 Centro Governador Valadares/MG 35010-177

\section{ALCIELIS DE PAULA NETO alcielisneto@gmail.com}

\section{Mestre em Administração pela UFLA}

Instituição de vinculação: Universidade Federal de Juiz de Fora - UFJF

Governador Valadares/MG - Brasil

Áreas de interesse em pesquisa: Estratégia; Empreendedorismo; Terceiro Setor; Administração Pública.

\section{MARLUSA GOSLING mg.ufmg@gmail.com \\ Doutora em Administração pela UFMG/CEPEAD}

Instituição de vinculação: Universidade Federal de Minas Gerais - UFMG/CEPEAD

Belo Horizonte/MG - Brasil

Áreas de interesse em pesquisa: Marketing turístico, marketing de experiências, pesquisa mercadológica. 